\title{
Risk Factors of Hypertension among Diabetic Patients from Yaoundé Central Hospital and Etoug-Ebe Baptist Health Centre, Cameroon
}

\author{
Beryl Kemche, ${ }^{1}$ Brice Ulrich Saha Foudjo $\mathbb{D}^{2},{ }^{2}$ and Elie Fokou ${ }^{1}$ \\ ${ }^{1}$ Department of Biochemistry, University of Yaoundé I, PO Box 337, Yaoundé, Cameroon \\ ${ }^{2}$ Department of Biochemistry, University of Bamenda, PO Box 39, Bambili, Cameroon \\ Correspondence should be addressed to Brice Ulrich Saha Foudjo; sahabrice@yahoo.fr
}

Received 13 April 2020; Revised 17 May 2020; Accepted 26 May 2020; Published 16 June 2020

Academic Editor: Janet H. Southerland

Copyright (C) 2020 Beryl Kemche et al. This is an open access article distributed under the Creative Commons Attribution License, which permits unrestricted use, distribution, and reproduction in any medium, provided the original work is properly cited.

\begin{abstract}
Uncontrolled blood pressure is a threat to diabetic patients' life. The aim of this study was to identify risk factors of hypertension among diabetic patients at different stages from Yaoundé Central Hospital and Etoug-Ebe Baptist Health Center of Cameroon. A hospital-based cross-sectional study was conducted for 6 months, and 109 participants (types 1 and 2), aged 24-81 years, were enrolled using simple random sampling. A pretested structured questionnaire was used to collect sociodemographic data, habitual behaviors, clinical history blood pressure, and anthropometric measures. The prevalence of hypertension was $86.2 \%$. Of the total, $13.8 \%$ participants were normotensive, $32.1 \%$ stage 1 hypertensive, and $54.1 \%$ stage 2 hypertensive. Being a male $(p=0.046)$ and not smoking $(p=0.036)$ were negatively associated with stage 1 hypertension whereas eating less than 3 times $(p=0.046)$ and duration of diabetes greater than 9 years among women $(p=0.039)$ were positively associated. Age above 40 years $(p=0.002)$ was negatively associated with stage 2 hypertension. However, age above 40 years had a negative effect among Christian, less educated diabetics, people having diabetes for more than 9 years, and those on medical treatment $(5.556 \leq$ specific $\mathrm{OR} \leq 10.278)$. Duration of diabetes (age-adjusted $\mathrm{OR}=1.155 ; p=0.003)$ and abnormal waist circumference (crude $\mathrm{OR}=4.074 ; p=0.024$ ) were positively associated with stage 2 . Abnormal waist-to-hip ratio (crude $\mathrm{OR}=3.773 ; p=0.028$ ) and feeding rate greater than 2 times a day (WHR-adjusted $\mathrm{OR}=3.417 ; p=0.046$ ) were positively associated with hypertension (stages 1 and 2). This study suggests that hypertension, present at its two stages, is a serious health issue among diabetic patients. Thus, appropriate intervention should be put in place to prevent and control hypertension by managing identified risk factors.
\end{abstract}

\section{Introduction}

Hypertension is becoming a serious concern in low- and middle-income countries based on the statistics. The prevalence of high blood pressure in sub-Saharan African ranges between $14.5 \%$ in rural Eritrea [1], 32.9\% in semiurban Ghana [2], and $40.1 \%$ in urban South Africa [3]. In Cameroon, hypertension is still uncommon in rural Cameroon but occurs frequently in urban community. The prevalence spans from $5.7 \%$ in rural settings [4] to $47.5 \%$ in urban milieu [5], with a national average survey of $31.0 \%$ [6]. The burden of hypertension is forecast to increase by 2025 as it is pre- dicted to reach a total of 1.56 billion worldwide [7]. This rise is clearly associated with the adoption of Western lifestyles by people in developing countries. The increase of morbidity and mortality from cardiovascular diseases related to hypertension is expected to follow [8-10].

Recent studies carried out worldwide have shown that the expected rise is also related to the scourge in the prevalence of diabetes among other risk factors [7, 11]. Epidemiologic studies have depicted that hypertension occurrence was 1.52 times greater among diabetic patients than in an approximately matched nondiabetic cohort $[7,12,13]$. Thus, managing hypertension among diabetics would lead to a drastic 
reduction of its incidence.

Several hypotheses were conjectured to explain the pathogenic relationship between hypertension and diabetes mellitus, and these include (i) insulin resistance produces stimulatory effects on the sympathetic nervous system and the renin-angiotensin system and (ii) abnormalities in catecholamines and sodium metabolism [14-16]. Nevertheless, hypertension is asymptomatic and is usually diagnosed incidentally or after major organ damage has occurred [17].

Independent risk factors for hypertension in the general population are known, among others, to be age, low educational status, being married, obesity, high dietary salt intake, low dietary intake of calcium and potassium, alcohol consumption, psychosocial stress, low levels of physical activity, and family history of hypertension [18-22]. So far, few risk factors of hypertension have been highlighted among diabetics in some countries (India, Nigeria, Benin, and United Arab of Emirates), namely, age above 55 years, abdominal obesity, and duration of diabetes [23-26]. Duration in diabetes was found to be the most common.

The epidemiology and etiology of hypertension in Cameroon are not well investigated, particularly among diabetics where no study has been carried out so far. From a study conducted in the USA, Berlowitz et al. [27] reported that diabetic patients received less intensive antihypertensive medication therapy than patients without diabetes. Thus, the main aim of this study was to identify risk factors among diabetics visiting Yaoundé Central Hospital and Etoug-Ebe Baptist Health Center. It will provide further information regarding the burden of hypertension and its risk factors to inform health policies and plan further interventions.

\section{Materials and Methods}

2.1. Clinical Settings. The study was conducted at the Yaoundé Central Hospital and the Etoug-Ebe Baptist Health Center, both located in the capital city of Cameroon. These two health centers were chosen as they have diabetes units. The work was conducted in these two health centers due to the scarcity of diabetic patients in Cameroon (prevalence of 4.3\%). The Yaoundé Central Hospital is Cameroon's largest hospital and a 381-bed tertiary level general teaching hospital. It employs nearly 800 staff and possesses the National Center for Hypertension and Diabetes. The Etoug-Ebe Baptist Health was the first CBC health facility in the Francophone Cameroon. It serves at least 350 patients daily.

2.2. Study Design and Period. A hospital-based crosssectional study was conducted between 01 June 2011 and 30 November 2011 to determine the hypertension's prevalence and its risk factors among diabetic outpatients.

2.3. Selection of Participants. As no study exists on hypertension among diabetic patients in Cameroon; the prevalence of diabetes in Cameroon was used to calculate the sample size. Considering a prevalence of $4.3 \%$, a $95 \%$ confidence intervals $(z=1.96)$, a precision of $5 \%$, and a nonresponse rate of $10 \%$, the sample size is 72 diabetic individuals. In the end, 109 eli- gible and consenting candidates were recruited using a simple random sampling.

2.4. Inclusive Criteria. All patients with either type 1 or type 2 diabetes and hypertensive or not were included in the study. They were all greater than 20 years old.

2.5. Data Collection. A structured questionnaire that included general information on sociodemographic characteristics (marital status, gender, religion, education level, age, and profession), habitual behaviors (sport activity, sport duration, feeding rate, alcohol, and smoking intake), clinical history (duration in diabetes, type of diabetes, family history of diabetes, dietary treatment, and medical treatment), and anthropometry (waist-to-hip ratio, waist circumference, BMI, and systolic and diastolic blood pressures) was used for data collection. The new classification of blood pressure was used based on the 2017 ACC/AHA/AAPA/ABC/ACP$\mathrm{M} / \mathrm{AGS} / \mathrm{APhA} / \mathrm{ASH} / \mathrm{ASPC} / \mathrm{NMA} / \mathrm{PCNA}$ Guideline [28]: normal blood pressure (systolic blood pressure (SBP) $<120 \mathrm{mmHg}$ and a diastolic blood pressure (DBP) of $<80 \mathrm{mmHg})$ elevated blood pressure $(120 \mathrm{mmHg} \leq \mathrm{SBP} \leq 129 \mathrm{mmHg}$ and $\mathrm{DBP}<80 \mathrm{mmHg})$, hypertension stage $1(130 \mathrm{mmHg} \leq \mathrm{SBP} \leq 139 \mathrm{mmHg}$ or 80 $\mathrm{mmHg} \leq \mathrm{DBP} \leq 89 \mathrm{mmHg})$, and hypertension stage 2 (SBP $\geq 140 \mathrm{mmHg}$ or $\mathrm{DBP} \geq 90 \mathrm{mmHg}$ ). Body mass index (BMI), waist-hip ratio, and waist circumference were measured and classified in accordance with the WHO guidelines [29].

2.6. Parameter Measurements. BP was measured using a mercury sphygmomanometer (adult size) by the auscultatory method. Blood pressure was taken while the patient was in a sitting position, from the right arm after the patient rested for at least 5 minutes before measurement. Two readings were taken at a $5 \mathrm{~min}$ interval, and the average of the two readings was reported. In case of a difference of $>5 \mathrm{mmHg}$ in the readings, two more readings were taken in a similar manner, and the average of all readings was reported. The point at which the first Korotkoff sound was heard was taken as systolic blood pressure (SBP), and the diastolic blood pressure (DBP) was taken to be the point at which the sound disappeared.

Weight and height were measured with participants standing without shoes and wearing light clothing. Weight was measured using a digital weighing scale. The scale was calibrated to the zero level before each measurement and was tested for repeatability of the measures. Height was measured by using a stadiometer while the patient was in an upright position.

Waist and hip circumferences were measured by using a flexible tape meter at both the level just above the iliac crest and at the maximum circumference of the hip, respectively.

2.7. Data Analysis. The data were entered and cleaned in MS Excel 2010 and exported to IBM/SPSS Windows version 20 (IBM Corporation, Armonk, NY, USA). Continuous variables were summarized as mean \pm standard error (SBP and DBP) while categorical variables were summarized as frequencies and proportions. Chi-square was used to analyze 
the associations between different qualitative variables. An unpaired $t$-test was used to compare two means. A twotailed $z$-test was employed to compare two proportions. To determine the risk factors associated with hypertension, bivariate and multivariate logistic regression analyses were carried out. Bivariate odds ratio estimation was followed by derivation of different multivariate models through logistic regression with forward entry and forward step-wise methods, and the best multivariate derived model was selected. This approach was used to adjust the odds ratios for confounders. $p<0.05$ was considered statistically significant.

2.8. Data Quality Control. Surveyors were trained for 1 day, and a presurvey was conducted on 14 eligible diabetic patients to ensure consistency, reliability, and to reduce intra- and interobserver variation. Supervision was done by the main investigators throughout the data collection and analysis.

2.9. Ethical Consideration. Ethical clearance, Authorization No. 232/CNE/SE/2011, was obtained from the Cameroon Ethics Committee. Additional authorization was obtained from both the National Center for Hypertension and Diabetes of the Yaoundé Central Hospital and the Cameroon Baptist Convention Health Board of Etoug-Ebe Baptist Health Center. Written informed consent was obtained from participants after comprehensive explanation of the scope and procedure of the study in English or French when necessary. The anonym of participants was kept for an indefinite period of time.

\section{Results}

3.1. Socio-Demographic Characteristics. A total 109 participants were enrolled in the study and among them, $60.6 \%$ were women and $39.4 \%$ men. The age range was from 24 years to 81 years, with a mean age of $55 \pm 11$ years. Nearly nine-tenths $(88.1 \%)$ of the participants was older than 40 years. Three-fourths of the participants were married (74.3\%), 21.1\% were widowed, and $4.6 \%$ were single. Approximately nine-tenths (89.9\%) was Christian and $10.1 \%$ Muslim. Nearly two-thirds had a secondary education level (61.5\%), $22.0 \%$ were illiterate, and $16.5 \%$ a postsecondary education level.

3.2. Clinical Characteristics. Nearly four-fifths (81.7\%) of the participants had type 2 diabetes, and $18.3 \%$ had type 1 diabetes. The duration of diabetes in this study varied from few months to 29 years. Seventy-five participants $(68.8 \%)$ have been having diabetes for less than 10 years and 34 participants $(31.2 \%)$ for more than 9 years. Sixty-two participants (56.9\%) had at least one parent that was diabetic, and fortyseven participants (43.1\%) had no family history of diabetes. Nearly $40.4 \%$ of the participants were overweight, $33.0 \%$ were obese, and $25.7 \%$ had a normal weight. From the 109 participants, $87.2 \%$ of the participants had abnormal waist circumference, and $12.8 \%$ had a normal waist circumference. Seventeen participants out of twenty (85.3\%) had an abnormal waist-to-hip ratio, and three participants out of twenty
(14.7\%) had a normal waist-to-hip ratio. Of the total, $83.5 \%$ of the participants were on dietary treatment, and $92.7 \%$ were on medical treatment. The rate of consumption of alcohol in the studied population was distributed as follows: rarely (32.1\%), moderately (56.9\%), and highly (11.0\%). The rate of smoking was distributed as follows: never (92.7\%), moderately $(4.6 \%)$, and highly $(2.8 \%)$. The daily feeding rate was distributed as follows: 1 to 2 times (33.0\%), 3 to 4 times $(64.2 \%)$, and more than 4 times $(2.8 \%)$. In this population, $77.1 \%$ practiced sport as physical activity, and $22.9 \%$ did not. The average duration of sport was $49 \pm 5 \mathrm{~min}$.

Even though all the study population was on dietary treatment and/or medical treatment, no improvement of the BMI (Phi $=0.036, p=0.933)$, waist-to-hip ratio (Phi $=-0.001, p=0.996)$, alcohol consumption $(\mathrm{Phi}=0.113$ , $p=0.500)$, smoking rate $(\mathrm{Phi}=0.137, p=0.360)$, waist circumference (Phi $=0.022, p=0.821)$, and feeding rate (Phi $=0.052, p=0.864)$ was observed over time (duration in diabetes).

3.3. Pattern of Hypertension among Diabetics. Of the total, the mean value of the systolic blood pressure was $138 \pm 21$ $\mathrm{mmHg}$, and the mean value of the diastolic blood pressure was $85 \pm 11 \mathrm{mmHg}$. No significant difference was observed in the mean values of SBP $(t=0.403, p=0.689)$ and DBP $(t=-0.319, p=0.750)$ of hypertensive diabetics in both genders. Age had no effect on the mean value of DBP $(t=-1.347$ $, p=0.181)$ and had a significant effect on the mean value of SBP $(t=-4.162, p \leq 0.001)$. Participants older than 40 years old $(140 \pm 2 \mathrm{mmHg}$ ) had a high value of SBP when compared to those not older than 40 years old $(125 \pm 3 \mathrm{mmHg})$.

Among the study population, $13.8 \%$ were normotensive, $32.1 \%$ stage 1 hypertensive, and $54.1 \%$ stage 2 hypertensive. The prevalence of hypertension among diabetics was $86.2 \%$. There was no statistical difference of prevalence of hypertension among women, $81.8 \%$, and men, $93.0 \%,(z=1.66$; $p=$ 0.097). There was no statistical difference of hypertension prevalence among type 1 diabetics, $85 \%$, and type 2 diabetics, $86 \%,(z=-0.178 ; p=0.859)$. The age range $(\mathrm{Chi}=6.639, p$ $=0.036)$ was statistically significant among the hypertension categories (Table 1). Stage 2 hypertensive diabetics were older than normotensive diabetics with both having equal number of old people as stage 1 hypertensive diabetics. The sex $\left(\mathrm{Chi}^{2}=2.988, p=0.224\right)$ did not significantly change in each hypertension category (Table 1).

3.4. Risk Factors of Hypertension among Diabetics. Odds ratios were calculated for risk factors found to be associated with hypertension at different stages among diabetics (Table 2). Four risk factors were associated with stage 1 hypertension occurrence among normotensive diabetics: gender $(p=0.046)$, feeding rate $(p=0.046)$, duration of diabetes $(p=0.039)$, and smoking status $(p=0.036)$. Three risk factors were identified that caused the development of stage 2 hypertension among stage 1 hypertensive diabetics: age $(p=0.002)$, duration of diabetes $(p=0.003)$, and waist circumference $(p=0.024)$. The overall development of hypertension (stages 1 and 2 ) was governed by three risk factors: 
TABle 1: Age- and gender-wise distribution of diabetic patients based on their systolic and diastolic blood pressure.

\begin{tabular}{lccc}
\hline Factors & Normotensive & $\begin{array}{c}\text { Stage 1 } \\
\text { hypertensive }\end{array}$ & $\begin{array}{c}\text { Stage 2 } \\
\text { hypertensive }\end{array}$ \\
\hline $\begin{array}{c}\text { Age (years) } \\
>40 \text { years }\end{array}$ & $11^{\mathrm{a}}(73.3 \%)$ & $29^{\mathrm{ab}}(82.9 \%)$ & $56^{\mathrm{b}}(94.9 \%)$ \\
$\leq 40$ years & $4(26.7 \%)$ & $6(17.1 \%)$ & $3(5.1 \%)$ \\
& $\mathrm{Chi}^{2}=6.639 ;$ & & \\
Statistics & $p=0.036$ & & \\
Gender & $35(36.4 \%)$ & $19(54.3 \%)$ & $12(80.0 \%)$ \\
Female & $24(63.6 \%)$ & $16(45.7 \%)$ & $3(20.0 \%)$ \\
Male & $\mathrm{Chi}^{2}=2.988 ;$ & & \\
Statistics & $p=0.224$ & & \\
\hline
\end{tabular}

Frequencies carrying the same superscript letter on the same row were statistically significant $(p<0.05)$.

waist-to-hip ratio $(0.028)$, smoking status $(p=0.043)$, and feeding rate $(p=0.046)$.

The results showed that being a male decreased the probability by $94.2 \%$ (adjusted OR $=0.058 ; 95 \%$ CI $0.004-0.956$ ) of developing stage 1 hypertension among normotensive diabetics. When exploring risk factors in each gender using univariate analysis, smoking status $(p=0.035)$ and feeding rate $(p=0.027)$ were the influencing risk factors in men whereas duration of diabetes $(p=0.038)$ was the one in women.

Eating more than 2 times a day increased the risk by 6.478 (95\% CI 1.035-40.533) of developing stage 1 hypertension. Not smoking decreased the probability by $98.3 \%$ (adjusted OR $=0.017$; 95\% CI $0.000-0.769$ ) of developing stage 1 hypertension. Surprisingly, long duration of diabetes seemed to decrease the probability of developing stage 1 hypertension. However, by stratifying this association with gender, it was observed that the risk of developing stage 1 hypertension among normotensive females with more than 9 years of diabetes was 5.143 times (95\% CI 1.033-25.602) higher than those with less than 10 years of diabetes. Among male, the association was nonsignificant $(p=0.943)$.

Stage 1 hypertensive diabetics with an age above 40 years old were 0.916 times (95\% CI $0.866-0.969$ ) more likely to become stage 2 hypertensive patients than those younger than 41 years old. When stratifying separately this association with the other 18 variables, duration of diabetes less than 10 years $(p=0.006)$, being on medication treatment $(p=0.023)$, education level less than First School Leaving Certificate (FSLC) $(p=0.015)$, and being Christian ( $p=0.027)$ were found to be significant. Independent stratification with duration of diabetes less than 10 years, being on medication treatment, having an education level less than FSLC, and being Christian increased the risk of developing stage 2 hypertension among stage 1 hypertensive patients above 40 years old by 7.167 (95\% CI 1.557-32.981), 5.778 (95\% CI 1.091-30.584), 10.278 (95\% CI 1.117-94.601), and 5.556 (95\% CI 1.049-29.434), respectively. Thus, duration of diabetes less than 10 years, being on medication treatment, and having an education level less than FSLC were negative confounders.
Age-adjusted odds ratio of duration of diabetes showed that for every 1 year of diabetes, the odds of becoming stage 2 hypertensive patients increased by 1.155 (95\% CI 1.0511.270 ) among stage- 1 hypertensive diabetics. Abnormal waist circumference among stage-1 hypertensive diabetics increased the risk by 4.074 (95\% CI 1.126-14.735) of developing stage 2 hypertension.

The examination of the determinants that allowed to shift from normotensive diabetics to hypertensive diabetics (stages 1 and 2) gave the following results: waist-to-hip ratio $(p=0.028)$, smoking status $(p=0.043)$, and feeding rate ( $p=0.046$ ) were associated with the risk of developing hypertension. Normotensive diabetics with abnormal waist-to-hip ratio were 3.773 times (95\% CI 1.087-13.091) more likely to develop hypertension than those with a normal waist-to-hip ratio. Using a univariate analysis, smoking seemed to reduce the risk of developing hypertension by $77.5 \%$. However, after adjusting for waist-to-hip ratio, smoking was found to be nonsignificant. Normotensive diabetics, eating at least 3 times a day, were 3.417 times (95\% CI 1.019-11.455) more likely to develop hypertension than those eating at most 2 times a day.

\section{Discussion}

The prevalence of hypertension was high among diabetics $(86.2 \%)$ in the two health centers. However, lower prevalence rates of $54.2 \%$ and $70.4 \%$ were reported among Nigerian and Moroccan diabetic populations, respectively [30,31]. One of the factors that could explain these lower prevalence rates may be the difference in the chosen cut-off point for high blood pressure selected by the authors, $\geq 140 / 90 \mathrm{mmHg}$. In this study the cut-off point was based on the new guidelines, which is $\geq 130 / 80 \mathrm{mmHg}$. If the same cut-off point was used $(\geq 140 / 90 \mathrm{mmHg}$ ), the prevalence of hypertension of this study would have been $54.1 \%$.

Among the study population, stage 2 hypertensive patients had the highest prevalence, followed by stage 1 hypertensive and normotensive patients. A reverse pattern was observed by Venugopal and Mohammed [32] among type 2 diabetics: $52.4 \%$ patients were prehypertensive, $18 \%$ patients were in stage 1 hypertension, and $7.6 \%$ had stage 2 hypertension.

Modifiable and nonmodifiable risk factors were identified at different stages of hypertension in this study. Under modifiable risk factors, there were waist-to-hip ratio, waist circumference, smoking status, and feeding rate. Age, gender, and duration of diabetes were the nonmodifiable risk factors.

When looking at the evolution of hypertension, age was found to influence only the development of stage 2 hypertension from stage 1 hypertensive diabetics. Its overall effect showed that getting older seemed to have protective effect against stage 2 hypertension. This overall effect was found to be disjointedly confounded by duration of diabetes less than 10 years, being on medication treatment, having an education level less than First School Leaving Certificate (FSLC) $(5.556 \leq$ specific odds ratios $\leq 10.278)$. These specific odds ratios were more consistent with the findings of Tabi Arrey et al. [22] that observed in the general population of 
TABLE 2: Risk factors at different hypertension stages among diabetic participants.

\begin{tabular}{|c|c|c|c|c|c|c|}
\hline \multirow{2}{*}{ Predictor variables } & \multirow{2}{*}{$\begin{array}{c}\text { Hypertensive } \\
\text { stage } 1(n=35) \\
N(\%)\end{array}$} & \multirow{2}{*}{$\begin{array}{c}\text { Normotensive } \\
(n=15) \\
N(\%)\end{array}$} & \multicolumn{2}{|c|}{ Univariate analysis } & \multicolumn{2}{|c|}{ Multivariate analysis } \\
\hline & & & OR (95\% CI) & $p$ value & OR $(95 \% \mathrm{CI})$ & $p$ value \\
\hline \multicolumn{7}{|l|}{ Gender } \\
\hline Male & $16(45.7 \%)$ & $3(20.0 \%)$ & 1 (reference) & & $\begin{array}{c}0.058 \\
(0.004-0.956)\end{array}$ & $0.046^{*}$ \\
\hline Female & $19(54.3 \%)$ & $12(80.0 \%)$ & $\begin{array}{c}0.297 \\
(0.071-1.240)\end{array}$ & 0.086 & 1 (reference) & \\
\hline \multicolumn{7}{|l|}{ Feeding rate } \\
\hline$\geq 3$ times a day & $23(65.7 \%)$ & $7(46.7 \%)$ & $\begin{array}{c}2.190 \\
(0.639-7.504)\end{array}$ & 0.208 & $\begin{array}{c}6.478 \\
(1.035-40.533)\end{array}$ & $0.046^{*}$ \\
\hline$<3$ times a day & $12(34.3 \%)$ & $8(53.3 \%)$ & 1 (reference) & & 1 (reference) & \\
\hline \multicolumn{7}{|l|}{ Duration of diabetes } \\
\hline$\geq 10$ years & $17(48.6 \%)$ & $4(26.7 \%)$ & $\begin{array}{c}2.597 \\
(0.692-9.747)\end{array}$ & 0.150 & $\begin{array}{c}0.856 \\
(0.739-0.992)\end{array}$ & $0.039^{*}$ \\
\hline$<10$ years & $18(51.4 \%)$ & $11(73.3 \%)$ & 1 (reference) & & 1 (reference) & \\
\hline \multicolumn{7}{|l|}{ Smoking status } \\
\hline Yes & $2(5.7 \%)$ & $3(20.0 \%)$ & $\begin{array}{c}0.242 \\
(0.036-1.633)\end{array}$ & 0.123 & $\begin{array}{c}0.017 \\
(0.000-0.769)\end{array}$ & $0.036^{*}$ \\
\hline No & $33(94.3 \%)$ & $12(80.0 \%)$ & 1 (reference) & & 1 (reference) & \\
\hline \multicolumn{7}{|l|}{ Occupation } \\
\hline Not retired or not a housewife & $21(60.0 \%)$ & $5(33.3 \%)$ & 1 (reference) & & $\begin{array}{c}0.435 \\
(0.080-2.361)\end{array}$ & 0.335 \\
\hline Retired or housewife & $14(40.0 \%)$ & $10(66.7 \%)$ & $\begin{array}{c}0.333 \\
(0.094-1.185)\end{array}$ & 0.084 & 1 (reference) & \\
\hline \multicolumn{7}{|l|}{ Tribe } \\
\hline Not from the west region & $18(51.4 \%)$ & $8(53.3 \%)$ & $\begin{array}{c}1.079 \\
(0.321-3.626)\end{array}$ & 0.902 & $\begin{array}{c}0.257 \\
(0.039-1.699)\end{array}$ & 0.159 \\
\hline West region & $17(48.6 \%)$ & $7(46.7 \%)$ & 1 (reference) & & 1 (reference) & \\
\hline $\begin{array}{l}\text { From stage } 1 \text { to stage } 2 \text { in } \\
\text { hypertension }\end{array}$ & $\begin{array}{c}\text { Hypertensive } \\
\text { stage } 2(n=59) \\
\end{array}$ & $\begin{array}{c}\text { Hypertensive } \\
\text { stage } 1(n=35)\end{array}$ & & & & \\
\hline \multicolumn{7}{|l|}{ Age } \\
\hline$>40$ years & $56(94.9 \%)$ & $29(82.9 \%)$ & $\begin{array}{c}3.862 \\
(0.900-16.574)\end{array}$ & 0.055 & $\begin{array}{c}0.916 \\
(0.866-0.969)\end{array}$ & $0.002^{*}$ \\
\hline$\leq 40$ years & $3(5.1 \%)$ & $6(17.1 \%)$ & 1 (reference) & & 1 (reference) & \\
\hline \multicolumn{7}{|l|}{ Duration of diabetes } \\
\hline$\geq 10$ years & $13(22.0 \%)$ & $17(48.6 \%)$ & $\begin{array}{c}0.299 \\
(0.121-0.739)\end{array}$ & $0.008^{*}$ & $\begin{array}{c}1.155 \\
(1.051-1.270)\end{array}$ & $0.003^{*}$ \\
\hline$<10$ years & $46(78.0 \%)$ & $18(52.4 \%)$ & 1 (reference) & & 1 (reference) & \\
\hline \multicolumn{7}{|l|}{ Waist circumference } \\
\hline Abnormal & $55(93.2 \%)$ & $27(77.1 \%)$ & $\begin{array}{c}4.074 \\
(1.126-14.735)\end{array}$ & $0.024^{*}$ & $\begin{array}{c}1.005 \\
(0.965-1.047)\end{array}$ & 0.802 \\
\hline Normal & $4(6.8 \%)$ & $8(22.9 \%)$ & 1 (reference) & & 1 (reference) & \\
\hline Normotensives to hypertensives & $\begin{array}{l}\text { Hypertensive } \\
\quad(n=94)\end{array}$ & $\begin{array}{l}\text { Normotensive } \\
\quad(n=15)\end{array}$ & & & & \\
\hline \multicolumn{7}{|l|}{ Waist-to-hip ratio } \\
\hline Abnormal & $83(88.3 \%)$ & $10(66.7 \%)$ & $\begin{array}{c}3.773 \\
(1.087-13.091)\end{array}$ & $0.028^{*}$ & $\begin{array}{c}0.000 \\
(0.000-0.007)\end{array}$ & $0.003^{*}$ \\
\hline Normal & $11(11.7 \%)$ & $5(33.3 \%)$ & 1 (reference) & & 1 (reference) & \\
\hline \multicolumn{7}{|l|}{ Smoking status } \\
\hline Yes & $5(5.3 \%)$ & $3(20.0 \%)$ & $\begin{array}{c}0.225 \\
(0.048-1.062)\end{array}$ & $0.043^{*}$ & $\begin{array}{c}0.175 \\
(0.031-1.008)\end{array}$ & 0.051 \\
\hline
\end{tabular}


TABLE 2: Continued.

\begin{tabular}{|c|c|c|c|c|c|c|}
\hline \multirow{2}{*}{ Predictor variables } & \multirow{2}{*}{$\begin{array}{c}\text { Hypertensive } \\
\text { stage } 1(n=35) \\
N(\%)\end{array}$} & \multirow{2}{*}{$\begin{array}{c}\text { Normotensive } \\
\quad(n=15) \\
N(\%)\end{array}$} & \multicolumn{2}{|c|}{ Univariate analysis } & \multicolumn{2}{|c|}{ Multivariate analysis } \\
\hline & & & OR $(95 \% \mathrm{CI})$ & $p$ value & OR $(95 \% \mathrm{CI})$ & $p$ value \\
\hline No & $89(94.7 \%)$ & $12(80.0 \%)$ & 1 (reference) & & 1 (reference) & \\
\hline \multicolumn{7}{|l|}{ Feeding rate } \\
\hline$\geq 3$ times a day & $66(70.2 \%)$ & $7(46.7 \%)$ & $\begin{array}{c}2.694 \\
(0.891-8.146)\end{array}$ & 0.072 & $\begin{array}{c}3.417 \\
(1.019-11.455)\end{array}$ & $0.046^{*}$ \\
\hline$<3$ times a day & $28(29.8 \%)$ & $8(53.3 \%)$ & 1 (reference) & & 1 (reference) & \\
\hline
\end{tabular}

OR: odds ratio; 95\% CI: 95\% confidence interval; $n$ : frequency, ${ }^{*} p$ value with this superscript was statistically significant $(p<0.05)$.

Cameroon that age above 40 years increased hypertension risk by 4.5 (95\% CI 3.0-6.8). In Benin, age above 55 years was positively associated with increasing risk of hypertension among diabetics using a bivariate analysis $(\mathrm{OR}=6.1, p \leq$ 0.001) [24]. In fact, the vascular system changes with age due to the alteration and relative reduction of elastic fibers that are replaced by collagen tissue in artery wall. This evolution induces more rigidity of arteries contributing to elevate blood pressure [24]. Moreover, with age, there is a decrease of baroreceptor sensitivity, an increase of responsiveness to sympathetic nervous system stimuli, an alteration of renal and sodium metabolism, and a modification of reninaldosterone relationship, thereby predisposing to high blood pressure [33].

Abnormal waist circumference (crude $\mathrm{OR}=4.074$ ) was associated with stage 2 hypertension. Similar results, with different intensity, were obtained in Benin [24]. The waist circumference (abdominal obesity) was positively associated $(\mathrm{OR}=1.9, p=0.036)$ with the risk of hypertension among Beninese diabetics. This suggested that diabetics with abdominal obesity had a high predisposition of developing stage 2 of hypertension. The mechanism is not entirely understood. However, research emphasized the major role of increased sympathetic activity in obesity-hypertension. Long-term sympathoactivation could raise arterial pressure by triggering peripheral vasoconstriction and by increasing renal tubular sodium reabsorption. Recent evidence indicates that leptin may represent a connection between excess adiposity and increased cardiovascular sympathetic activity [34].

Gender was observed to foster stage 1 hypertension among normotensive diabetics. Male diabetics had a low probability than female ones. However, Kingue et al. [6] showed that in the general population of Cameroon, males had an increased hypertension risk of 1.23 (95\% CI 1.1421.331) compared to females. This conclusion was also reached by many other researchers. This might either mean that in diabetes, women are more exposed to hypertension than men or the effect of duration of diabetes in women in this study had an important influence on hypertension occurrence compared to smoking and feeding rate in men as pointed out by the results.

Abnormal waist-to-hip ratio was positively associated with hypertension (both stages 1 and 2) among diabetics. This finding was also highlighted by Picon et al. [35] whose work showed that waist-to-hip ratio was associated with hypertension risk among Portuguese diabetics. In this study, BMI was not found to be a significant risk factor. Thus, this reiterated the fact that diabetics seem to be inclined to develop abdominal obesity as observed by Yadav et al. [36] with an increased risk of 1.56 (95\% CI 1.37-1.79) in the Indian population.

Not smoking decreased the risk of getting stage 1 hypertension among normotensive diabetics. Even though available data did not portray a direct causal relationship, Virdis et al. [37] believed that cigarette smoking associated with affecting arterial stiffness and wave reflection could have greater adverse effect on central blood pressure. Hypertensive smokers are more predisposed to develop severe forms of hypertension, including malignant and renovascular hypertension. This might be due to an accelerated atherosclerosis.

Feeding rate had the highest influence (adjusted odds ratios of 3.417 and 6.478 ) on hypertension compared to the other significant risk factors. In reality, it is dietary sodium daily intake that causes elevation of blood pressure while dietary potassium intake reduces hypertension risk [38]. Thus, in this study, increasing the feeding rate might be strongly related to the increase of dietary sodium.

Duration of diabetes was the only risk factor present at every stage of hypertension. Its impact was greater between stage 1 hypertensive diabetics and stage 2 hypertensive diabetics (adjusted $\mathrm{OR}=1.115$ ) than between normotensive diabetics and stage 1 hypertensive diabetics (adjusted OR = $0.856)$. In one study conducted in Nigeria, duration of diabetes was shown to be correlated to hypertension $(p=0.04)$ among type 2 diabetics [26]. In another study conducted in India, the prevalence of hypertension was shown to increase with the duration of diabetes [23]. This result may be related to chronic hyperglycemia resulting in endothelial suffering leading to thickening of the arterial wall and to a rise in blood pressure later [24].

Even though this survey has come up with important findings regarding the risk factors of hypertension among diabetics, there are certain limitations that should be pointed out. First of all, there was possibility that patients underreported their family history of diabetes, which was based on only self-reports. Secondly, the study involved type 1 and type 2 diabetics which may exhibit different characteristics that may distort relationship between hypertension and its actual risk factors. The fact that this was a hospital-based cross-sectional study indicates that this study may lack 
generalizability to the entire population. Finally, the small sample size used in this study compared to other studies may be unable to reflect the real effect of and identify all the risk factors.

\section{Conclusion}

The present study showed that hypertension has a high magnitude (prevalence of $86.2 \%$ ) among diabetics from the Yaoundé Central Hospital and the Etoug-Ebe Baptist Health Center. It also highlighted the fact that the nature of significant risk factors changed with hypertension evolution, except duration of diabetes that was present at each stage. Modifiable risk factors were waist-to-hip ratio, waist circumference, smoking, and feeding rates. Nonmodifiable risk factors were gender, age, and duration of diabetes. Thus, special care should be given to patients with more than 9 years of diabetes. Likewise, early identification of normotensive diabetics consuming sodium-rich diets, especially women, and/or smoking should be a priority. Among stage 1 hypertensive diabetics, care should be emphasized on patients older than 40 years and/or with abnormal waist circumference. Moreover, Christian and less educated diabetics should be sensitized on diabetes management. These findings also indicate the importance of carrying similar studies in different geographical regions of Cameroon to delineate the exact pattern of hypertension among diabetic patients across the country.

\section{Data Availability}

The data used to support the findings of this study are available from the corresponding author upon request.

\section{Conflicts of Interest}

The authors declare that there is no conflict of interest regarding the publication of this paper.

\section{References}

[1] J. Mufunda, G. Mebrahtu, A. Usman et al., "The prevalence of hypertension and its relationship with obesity: results from a national blood pressure survey in Eritrea," Journal of Human Hypertension, vol. 20, no. 1, pp. 59-65, 2006.

[2] F. P. Cappuccio, F. B. Micah, L. Emmett et al., "Prevalence, detection, management, and control of hypertension in Ashanti, West Africa," Hypertension, vol. 43, no. 5, pp. 10171022, 2004.

[3] R. Malhotra, T. Puone, C. Hoyo, and G. Hughes, "Prevalence and awareness of hypertension in an urban township of South Africa: compelling need for action," Ethnicity and Disease, vol. 18, no. 4, pp. 401-402, 2008.

[4] J. C. N. Mbanya, E. M. Minkoulou, J. N. Salah, and B. Balkau, "The prevalence of hypertension in rural and urban Cameroon," International Journal of Epidemiology, vol. 27, no. 2, pp. 181-185, 1998.

[5] A. Dzudie, A. P. Kengne, W. F. Muna et al., "Prevalence, awareness, treatment and control of hypertension in a selfselected sub-Saharan African urban population: a crosssectional study," BMJ Open, vol. 2, no. 4, pp. 1-10, 2012.
[6] S. Kingue, C. NdongNgoe, A. Menanga, B. Fesuh, C. Nouedoui, and W. F. T. Muna, "Prevalence and risk factors of hypertension in urban areas of Cameroon: a nationwide population-based cross-sectional study," The Journal of Clinical Hypertension, vol. 17, no. 10, pp. 819-824, 2015.

[7] P. M. Kearney, M. Whelton, K. Reynolds, P. Muntner, P. K. Whelton, and J. He, "Global burden of hypertension: analysis of worldwide data," The Lancet, vol. 365, no. 9455, pp. 217 223, 2005.

[8] N. Poulter, K. T. Khaw, B. E. Hopwood et al., "Blood pressure and its correlates in an African tribe in urban and rural environments," Journal of Epidemiology and Community Health, vol. 38, no. 3, pp. 181-185, 1984.

[9] A. Ogunlesi, B. Osotimehin, F. Abbiyessuku et al., "Blood pressure and educational level among factory workers in Ibadan, Nigeria," Journal of Human Hypertension, vol. 5, no. 5, pp. 375-380, 1991.

[10] C. H. Bunker, F. A. Ukoli, M. U. Nzwankwo et al., "Factors associated with hypertension in Nigerian civil servants," Preventive Medicine, vol. 21, no. 6, pp. 710-722, 1992.

[11] I. Hajjar, J. M. Kotcher, and T. A. Kotchen, "Hypertension: trends in prevalence, incidence, and control," Annual Review of Public Health, vol. 27, no. 1, pp. 465-490, 2006.

[12] G. H. Williams, "Hypertensive vascular disease," in Harrison's Principles of Internal Medicine, E. Braunwald, A. S. Fauci, D. L. Kasper, S. L. Hauser, and D. L. Longo, Eds., vol. 246pp. 14141430, McGraw Hill, 2001.

[13] A. N. Alabi, F. M. Onuoha, and K. M. Alabi, "Awareness of obesity as a cardiovascular risk factor among different occupational groups in a primary care clinic in Nigeria," Nigerian Journal of Family Practice, vol. 5, pp. 13-18, 2014.

[14] R. J. Jarrett, H. Keen, M. McCartney et al., "Glucose tolerance and blood pressure in two population samples: their relation to diabetes mellitus and hypertension," International Journal Epidemiology, vol. 7, no. 1, pp. 15-24, 1978.

[15] F. Cambien, "Relationship between obesity and arterial hypertension," Nouvelle Presse Medicale, vol. 11, no. 49, pp. 36413646, 1982.

[16] P. L. Drury, "Diabetes and arterial hypertension," Diabetologia, vol. 24, no. 1, pp. 1-9, 1983.

[17] World Health Organization, The World Health Report 2002: Reducing Risks, Promoting Healthy Life, World Health Organization, Geneva, Switzerland, 2002.

[18] World Health Organization, "Hypertension control. Report of a WHO Expert Committee," World Health Organization Technical Report Series, vol. 862, pp. 1-83, 1996.

[19] T. G. Pickering, "The effects of environmental and lifestyle factors on blood pressure and the intermediary role of the sympathetic nervous system," Journal of Human Hypertension, vol. 11, Supplement 1, pp. S9-S18, 1997.

[20] A. V. Chobanian, G. L. Bakris, H. R. Black et al., "Seventh report of the Joint National Committee on prevention, detection, evaluation, and treatment of high blood pressure," Hypertension, vol. 42, no. 6, pp. 1206-1252, 2003.

[21] T. A. Kotchen, "Hypertension control," Hypertension, vol. 49, no. 1, pp. 19-20, 2007.

[22] W. Tabi Arrey, C. Akem Dimala, J. Atashili, J. Mbuagbaw, and M. G. Lobe, "Hypertension, an emerging problem in rural Cameroon: prevalence, risk factors, and control," International Journal of Hypertension, vol. 2016, 6 pages, 2016. 
[23] D. Priya, K. Dudhal, G. M. Khakse, R. Meshram, P. A. Hiwarkar, and S. N. Wahab, "Prevalence of hypertension among type 2 diabetes patients attending diabetes clinic at tertiary care hospital, Nagpur," International Journal of Science, Environment and Technology, vol. 2, no. 6, pp. 1401-1406, 2013.

[24] D. Amoussou-Guenou, A. Wanvoegbe, A. Agbodandé et al., "Prevalence and risk factors of hypertension in type 2 diabetics in Benin," Journal of Diabetes Mellitus, vol. 5, no. 4, pp. 227232, 2015.

[25] B. M. Mussa, Y. Abduallah, and S. Abusnana, "Prevalence of hypertension and obesity among Emirati patients with type 2 diabetes," Journal of Diabetes \& Metabolism, vol. 7, no. 1, pp. 1-5, 2016

[26] F. M. Onuoha and J. I. Egwim, "Hypertension amongst the diabetic patients assessing care in a primary care setting in South-Eastern, Nigeria," Journal of diabetes and clinical studies, vol. 1, no. 1, pp. 1-6, 2017.

[27] D. R. Berlowitz, A. S. Ash, E. C. Hickey, M. Glickman, R. Friedman, and B. Kader, "Hypertension management in patients with diabetes: the need for more aggressive therapy," Diabetes Care, vol. 26, no. 2, pp. 355-359, 2003.

[28] P. K. Whelton, R. M. Carey, W. S. Aronow et al., "2017 ACC/AHA/AAPA/ABC/ACPM/AGS/APhA/ASH/ASPC/NMA/PCNA guideline for the prevention, detection, evaluation, and management of high blood pressure in adults: a report of the American College of Cardiology/American Heart Association Task Force on Clinical Practice Guidelines," Journal of the American College of Cardiology, vol. 71, no. 19, p. 122, 2018.

[29] World Health Organization, Physical status: the use and interpretation of anthropometry. WHO TRS 854-859, World Health Organization, 1995, Geneva, 1995.

[30] B. C. Unadike, A. Eregie, and A. E. Ohwovoriole, "Prevalence of hypertension amongst persons with diabetes mellitus in Benin City, Nigeria," Nigeria Journal of Clinical Practice, vol. 4, pp. 300-302, 2011.

[31] M. Berraho, Y. EL Achlab, A. Benslimane, K. EL Rhazi, M. Chikri, and C. Nejjari, "Hypertension and type 2 diabetes: a cross-sectional study in Morocco (EPIDIAM STUDY)," Pan African Medical Journal, vol. 11, p. 52, 2012.

[32] K. Venugopal and M. Z. Mohammed, "Prevalence of hypertension in type-2 diabetes mellitus," CHRISMED Journal of Health and Research, vol. 1, no. 4, pp. 223-227, 2014.

[33] M. A. Weber, J. M. Neutel, and D. G. Cheung, "Hypertension in the aged: a pathophysiologic basis for treatment," American Journal of Cardiology, vol. 63, no. 16, pp. 25-32, 1989.

[34] K. Rahmouni, M. L. Correia, W. G. Haynes, and A. L. Mark, "Obesity-associated hypertension: new insights into mechanisms," Hypertension, vol. 45, no. 1, pp. 9-14, 2005.

[35] P. X. Picon, C. B. Leitão, F. Gerchman et al., "Waist measure and waist-to-hip ratio and identification of clinical conditions of cardiovascular risk: multicentric study in type 2 diabetes mellitus patients," Arquivos Brasileiros de Endocrinologia \& Metabologia, vol. 51, no. 3, pp. 443-449, 2007.

[36] S. Yadav, R. Boddula, G. Genitta et al., "Prevalence \& risk factors of pre-hypertension \& hypertension in an affluent north Indian population," Indian Journal of Medical Research, vol. 128, no. 6, pp. 712-720, 2008.
[37] A. Virdis, C. Giannarelli, M. Fritsch Neves, S. Taddei, and L. Ghiadoni, "Cigarette smoking and hypertension," Current Pharmaceutical Design, vol. 16, no. 23, pp. 2518-2525, 2010.

[38] K. S. Reddy and M. B. Katan, "Diet, nutrition and the prevention of hypertension and cardiovascular diseases," Public Health Nutrition, vol. 7, no. 1A, pp. 167-186, 2004. 